\title{
DORFMAN, CUENTISTA COMPROMETIDO
}

\author{
Por \\ JUAN CLARO-MAYO \\ University of Pittsburgh
}

Ariel Dorfman en su nuevo libro de cuentos, Cría ojos ${ }^{1}$, ha invertido los términos del proverbio popular "Cría cuervos y te sacarán los ojos". En tanto que criar cuervos supone un peligro inminente, criar ojos supone una necesidad terapéutica y profundamente humana. Los ojos que se han de criar para mirar e iluminar, habrán de ser una suerte de toma de conciencia de la realidad: lá situación del pueblo chileno bajo la dictadura del gobierno militar desde 1973.

Dorfman, profesor, ensayista y crítico chileno, actualmente en el exilio, nació en 1942. Era, antes del golpe, profesor de Literatura en la Universidad de Chile, especializado en el estudio de literatura infantil. Entre sus obras más importantes relacionadas con la crítica y el ensayo, se destacan: El teatro de Harold Pinter (1968); Imaginación y violencia en América (1970); Para leer al Pato Donald (junto a Armando Mattelart), con una primera edición en Chile (1971), y la segunda en La Habana, Cuba (1974). También tiene novela: Moros en la costa, y otros ensayos: Superman y sus amigos del alma (con Manuel Jofré) y Ensayos quemados en Chile. Participó en la colectiva editorial de la Unidad Popular "Quimantú". Recientemente publicó en estudio de comunicación de masas titulado La última aventura del Llanero Solitario (Costa Rica, 1979).

Cría ojos muestra que estamos ante un buen escritor. El oficio se integra al que tiene algo que decir. Su dominio de estructuras narrativas no se da gratuitamente. Hay una ligazón interna entre lo contado y el cómo. El lenguaje depende de la materia y perspectiva de lo narrado, según haya un narrador no objetivado en la historia, o un narrador protagonista. De ahí que resulte una cosa viva, auténticamente chilena, en cuento tiene la expresión de valores y problemas de un pueblo.

El libro se divide en tres secciones: "Párpados", "Cuervos" y "Ojos", respectivamente. Las dos primeras contienen cuatro cuentos cada una, y seis la última. "Párpados" supone ya un modo de ver, y así los cuatro cuentos que lo conforman nos presentan una visión: los personajes se ven enfrentados a un mundo hostil, temible e implacable. Es el régimen de

1 México: Editorial Nueva Imagen, 1979. 
terror implantado por la Junta Militar de Chile. Lo que se palpa es esa atmósfera nerviosa, exasperante en que los personajes deben respirar y habitar, más que vivir. "Párpados" es una serie de perspectivas que coinciden en la denuncia de una realidad, a la que sus personajes empiezan a ver y a oponerse, o simplemente ya se han opuesto y deben sufrir las sanciones de la dictadura. Caracteriza a estos personajes la enorme dignidad ante el sufrimiento y el atropello, su inagotable esperanza, a pesar del terror constante. Ellos pueden ser el padre, viejo sindicalista, que se alza como una antorcha joven ante su propio hijo 'milico'; o del editor que tiene una visión de la realidad de su vida a través de un extraño libro que debe juzgar; o de los niños que llevan a sus juegos la conflictiva situación que viven sus padres-y ellos mismos-, donde se enfrentan el temor al allanamiento policial, con la heroica lucha por la resistencia. El último cuento "Siempre supe", el más breve, ya no identifica siquiera al personaje; lo presenta desde una perspectiva a la distancia, al modo de una cámara que no alcanza a registrar todo; pero aquello que registra es lo suficiente para crear magistralmente el mundo sórdido, la atmósfera irrespirable de terror que se lanza sobre una chica, y que bajo un disfraz de cierta cortesía la hace subir a un auto para hacer un viaje del que ella no regresará jamás. Se narran sólo algunos movimientos que se logran percibir a la distancia. No es necesario más para advertir que se trata de una situación reiterada hasta la saciedad por la fuerza represiva, hasta el punto que el narrador testigo puede usar el "tú" con la joven, familiarmente, y adivinar, relatando desde la distancia, hasta detalles mínimos, como por ejemplo el latir del reloj pulsera de ella:

Sólo se puede percibir la parte trasera del auto, y en un hueco que admite el juego de las hojas del árbol con los rayos de este verano demasiado tempranero, algún color borroso que podría ser tu pelo o la nuca que tiembla bajo tu pelo. Si no fuera por el moroso e inconmovible avance del minutero en tu reloj pulsera, allá donde la lenta sangre de tu brazo se encuentra y fluye con la misteriosa sangre de tu mano, si no fuera por la rotación imperceptible de este planeta, se podría pensar que el tiempo se ha estancado, que el movimiento se ha hecho parálisis, que el silencio es definitivo, y que ahí se quedarán para siempre, tú, ellos, el auto, la calle.

La fuerza está en esa contención, en esa atmósfera creada, donde hasta el día parece detenerse, menos la sangre de la mano de la joven.

A pesar del mundo crudo y despiadado que oprime, hay en estos relatos una cálida ternura que se establece entre sus personajes. Estos personajes - ya es bueno decirlo- no son simplemente producto de "literatura" o de la imaginación: son seres reales, el habitante diario y anónimo del pueblo de Chile llevado a la escritura. La ternura late en todos lados: en el conflicto del hijo milico y su padre cesante, ex-dirigente gremial en tiempos 
de Allende; la admiración del pueblo por el padre, hasta un desenlace en que se vislumbra un posible acuerdo:

El viejo repuso la olla en el fuego con mucha calma, tomándose el tiempo. Se colocó las dos manos en la cintura y me examinó.

Como el silencio se hizo pesado le tocó hablar a mi mamá.

- Bueno -dijo ella, - ahora estamos todos. Debes traer hambre, Lucho. ¿Qué te parece si preparo la comida?

Tardé un rato en contestar. No sabía qué hacer con mis ojos, pero finalmente terminé mirándolo a él, a mi viejo, a mi papá, parado allá como un demonio o como un santo al lado de la olla.

Los "párpados" que se abren son los del joven, que si bien no puede desertar del servicio militar -lo que podría implicarle un peligro mortalsiente en la figura paternal la presencia de valores vivos y fuertes, a pesar del hambre y la violencia. La intensidad de este bello relato es lo que nos ayuda a distinguir entre el simple panfleto y lo que es realmente literatura. La literatura es tal en cuanto es capaz de crear una verdadera comunicación, un fuerte remezón; el panfleto, en cambio, es aquella escritura que no logra traspasar la cáscara, sin fuerza para crear un mundo. Aun cuando ambos intentan reflejar una situación, una le da vida propia, y el otro no.

La segunda serie de cuentos "Cuervos" nos pone frente a personajes que forman parte o apoyan a la Junta Militar. Ya el rótulo "Cuervos" es aplastante: desde cadetes en busca de su primera experiencia sexual, pasando por un militar que exige una receta para adelgazar al médico que salvajemente tortura, hasta una esposa abandonada que escribe al consultorio sentimental, o un pobre cesante que encuentra trabajo como vendedor de un producto represivo y reaccionario, y que ha de acometer justamente contra el propio necesitado vendedor. El primer relato "Putamadre" nos presenta en el apodo-título un símbolo de un tipo real entre algunos sectores de los jóvenes de la burguesía acomodada y, en especial de la conciencia adquirida por adquirida por aquellos que integran las Fuerzas Armadas. Pasea en estos relatos toda la ideología conforme a los propósitos de la dictadura, la fraseología reiterada hasta el cansancio con aquello de que todo lo que se oponga al gobierno de Pinochet es "poco patriota" o "comunista", dándole a éstos términos las connotaciones más arbitrarias y falsas. El "Putamadre" es un cadete naval que repite esta ideología, haciéndose portador de una dignidad pretendidamente patriótica, pero cuya visión de la realidad tiene directa relación con la clase burguesa acomodada a la cual pertenece, cuyo sistema de valores es evidentemente contradictorio. Hay un desajuste entre lo que se proclama, la típica palabrería hueca sostenida desde el nivel oficial, y la acción real de este personaje. En tanto: que se habla de democracia y libertad, el 
"Putamadre" presenta una situación inmoral y delictual, la que ha sido posible gracias al apoyo y beneplácito del sistema. Con orgullo se justifica lo inconfesable: "había que castigar a los "upelientos" (apodo puesto por la burguesía a los que integraban la Unidad Popular chilena). La influencia del Putamadre sobre otro joven cadete en conflicto con los valores del sistema constituye la problemática del relato. Entre líneas se sugiere la violación brutal, por parte de los cadetes, de las jóvenes que trabajaron a favor de la Unidad Popular. En tanto que para la jerarquía militar se trata de un "botín de guerra" y un modo de castigar a esas "comunistas", el joven cadete ha rechazado su participación en la violación de una de esas chicas, lo que le ocasionará ser puesto en tela de juicio por jefes y compañeros. La reserva moral del joven, la fidelidad a sus principios, irá siendo minada poco a poco por el "Putamadre" con el incentivo de ayudarle a que obtenga su primera experiencia sexual. Al desembarco en California del Buque-Escuela "Esmeralda" (que fue usado como centro de tortura después del golpe), y ante el "boicot" de las prostitutas contra los marinos chilenos, el Putamadre ha de encontrar la diabólica solución. Planifica la violación de una chica norteamericana, con el pretexto de darle una lección por su participación contra el gobierno de Chile, violación que servirá además para iniciar sexualmente al joven cadete. Se establece una analogía entre la joven chilena a la que se negó violar y la norteamericana. Ambos casos son la variante de un mismo paradigma de un estado delictual, en el que el joven modifica su actitud. Su inicio sexual será también su inclusión dentro del degradado mundo al que ha empezado a pertenecer.

La última serie de cuentos se titula "Ojos" y sus personajes se ubican en una perspectiva esperanzada y esperanzadora. Ellos constituyen, a nivel individual o colectivo, consciente o inconscientemente, una resistencia contra el estado inhumano a que ha sido sometido todo aquel que discrepe con la verdad oficial y, más aún, contra todo aquel que no pertenezca al mundo de los "ejecutivos". En tanto que un sector de Chile duerme bajo los reflectores del cinematógrafo de la propaganda gubernamental, el sector popular vive en un estado de temor constante. Por eso los personajes de "Ojos" son personajes héroes: ellos han optado por ignorar toda la violencia que les amenaza y, en cambio, generan, a través de su actitud de combate, una visión profunda y valerosa, una respuesta iluminadora y digna de ejemplo. Los seis cuentos que incluye esta serie presentan esas características. En "Cuestión de tiempo", mediante un modo narrativo apostrófico, se dirige a un "tú" llamado "Borges", que no es sino el escritor Jorge Luis Borges real. La parodia a Borges va del mismo título, ya que el tiempo es el tema predilecto de los juegos borgianos de ficción. Pero este 
otro tiempo de Dorfman no es un juego; está dotado de la seriedad concreta del aquí y del ahora. El argumento inicial tiene relación con el cuento de Borges titulado "El milagro", en el que un hombre que va a ser ejecutado por un pelotón de fusilamiento obtiene la posibilidad fantástica de que el instante entre que se obsture el gatillo y la bala penetre al cuerpo se condense y alargue, de modo que el personaje pueda entregarse a escribir y completar una obra inconclusa. Una vez terminada, el tiempo vuelve a la normalidad, los soldados petrificados en el gesto se mueven nuevamente, y la bala entra al cuerpo. En el cuento de Dorfman, el soldado agresor es muerto por la bala de una pistola salida casi misteriosamente del prisionero, pero esta acción no es sino símbolo esperanzado de lo que realmente es un proyecto: no hay bala ni muerto en el presente; sólo la fuerza y decisión de una bala mental -y concretalanzada por el prisionero en su presente actual, contra un soldado represivo y sádico, cuyo destino habrá de demorar el tiempo que sea necesario para triunfar contra la dictadura. La bala entrará efectivamente al cuerpo del soldado en ese momento, y una vez que un tribunal legalmente constituido así lo determine. Esa bala cruzando el tiempo es un símbolo esperanzado que nada tiene que ver - dice el mismo narrador a Borges- con los juegos ficcionales:

Entiéndame, Borges: no se trata de un consuelo ni de un truco intelectual lleno de ríos de tigres ni de un juego de artimañas. Y nosotros también, Borges, tenemos derecho al tiempo, tenemos derecho a multiplicar el tiempo. La bala quedaría por ahí, caliente, decidida, audaz, inutilizada todavía por nosotros, guardada en algún hueco silencioso de dignidad, combate, esperanza que iríamos a conservar como fieras en medio de la derrota, como yo lo había sabido conservar en ese sótano en el filo de la medianoche irreal. La bala era una buena compañera, tardaría tantos años imposibles en cruzar el tiempo como la persona que la había disparado. Estaría ahí cerca, esperándonos. Compañera, Borges, esa es la palabra. (p. 152).

En otro cuento de esta serie, titulado "Y qué oficio le pondremos" (parafraseando una canción infantil) se presenta a una mujer de pueblo que debe ir a inscribir a su hijo al Registro Civil. Insiste en ponerle el mismo nombre de su hijo mayor, a pesar de la negativa del funcionario. Finalmente encuentra el nombre que de seguro habrá de agradar a su marido ausente: Salvador. Nombre simbólico que la emparienta con una figura y un pensamiento político: Salvador Allende. $Y$ que produce un secreto entendimiento afectivo con el funcionario del Registro Civil, contacto profundo que implica una cálida fraternidad, viva a pesar del silencio.

"Titán" es la acción heróica de un prisionero que aprovecha la amarga lección de sus dos hermanos asesinados por el gobierno militar, cuya falsa 
versión oficial le permitirá concebir un plan de escape descabellado y temerario. Atado a un catre logra burlar a la fuerza policial en su mismo reducto. El intento de fuga antes aducido a sus hermanos es ahora real y definitivo, y una promesa y una lección de lo que puede el valor, el único modo de vivir dignamente. El relato arroja luz en cuanto al camino a seguir, y en cuanto al sentido del libro entero:

Había robado el fuego de la vida, había exprimido desde el fondo de sí mismo el último color áspero que nunca duerme, se había atrevido a alumbrar la antorcha de la resistencia y pasarla de mano en mano hasta que todo el mundo aprendiera a criar ojos, había crecido en las raíces truncas de sus hermanos. (p. 173)

"Criar ojos" es, entonces, capturar un tipo de visión que guíe al triunfo. La lección de "Titán" es la del que ha abierto un camino en medio del terror y la oscuridad, como él mismo proclama:"

Esas palabras que yo solamente había anticipado porque soy una hoguera en que los demás habitantes de este mundo van a aprender a no tener miedo a la oscuridad. (p. 184)

$\mathrm{Y}$ por último, el rechazo a concebir la literatura como ficción y especulación borgiana, sino como testino real del propio cuerpo: “... probando que nadie me está soñando, que nadie me podrá manipular”. De ahí, la ironía contra el "Hacedor" de mundos y juegos con el tiempo. Ante una realidad conflictiva y agobiante la literatura debe ser registro, denuncia y llamado a la participación para el encuentro con los valores y la conducta que han de producir el cambio.

El último cuento se titula "La batalla de los colores". Al modo de un cuento infantil, se crea una realidad fantástica, en la que un coleccionista de pinturas de niños triunfa de la agresión militar gracias precisamente a la superrealidad otorgada por esas pinturas. El protagonista comienza a coleccionar dibujos de niños la misma mañana del derrocamiento de Allende por la Junta Militar. El absurdo que pareciera significar la recolección de pinturas en un momento así, comienza a tomar sentido a medida que se acrecienta la llegada de más y más pinturas, tanto de hijos de amigos de José como, luego, de miles de otros niños de todos los puntos del país. La cadena se hace interminable. Esas pinturas representan diversos motivos ligados a la familia, a la escuela, o a la vida de la nación, como así de otros motivos allegados a la ideología del gobierno de Allende. Esas pinturas constituyen una visión esperanzada en un mundo de valores plenos. La casa de José comienza a llenarse de dibujos, y él ya no puede hacer otra cosa que amontonarlos por todos lados. El control policial, de la sospecha absurda, llega a la agresión acostumbrada y sitia la casa del protagonista. Pero sucede algo inesperado: José no se rinde a balas ni a 
bombas lagrimógenas. Como en un laberinto de colores, ha ido escondiéndose en cada motivo pintado. Es decir, ha penetrado en una superrealidad llena de barcos que parten, de visitas a la maestra que ha tenido un hijo, o marchas escolares. Va saltando de un motivo a otro. Cuando los soldados reales logran penetrar a la casa, a medida que revisan esas pinturas, el enfrentamiento a los soldados dibujados, llenos de vigor e ideales, les provoca gran confusión y agotamiento. Ni los relevos de múltiples soldados hacen que la acción policial triunfe. Pero hay que señalar que más que la búsqueda fantástica como solución de una realidad desesperada, lo que han logrado esas pinturas infantiles es el rescate a través del color de un mundo también lleno de color, de una visión no contaminada y optimista. Además ellas registran el paso del que se va haciendo adulto ante la experiencia sombría de la Junta Militar. José, diseminado ahora entre las pinturas es inalcanzable ya para todos, no puede ser vencido. Pero también se ha adelantado al futuro a esperar, resguardando su tesoro de colores. El relato termina con una promesa llena de optimismo:

y éramos demasiados los que ya lo sembrábamos al viento de la mirada de los demás, a la tierra que iba a ser nuestra algún día y hoy también, que José se había ido en un tranvía de los colores más adultos posibles cargado de gallinas y huevos y burros de oro y que esperaba a todo el país en un futuro lleno de colinas rojas donde los niños volverían a pintar su liberación. (p. 229).

La coincidencia con El reino de este mundo de Carpentier, en cuanto a solución suprarreal del aquí y del ahora, habría que pensarla en lo que ambas obras tienen de rescate de un mundo, como paradigma de valores de certeza de recuperación. Bien lo dicen las últimas líneas del relato; lo que los niños volverán a pintar es la liberación.

El único modo de derrotar a los múltiples cuervos que amenazan a los personajes de Cría ojos - el pueblo chileno- es efectivamente criar ojos, es decir, multiplicar y profundizar la mirada liberadora, la que en actitud de combate desafíe al temor e instale la esperanza definitiva. 
